\title{
Enhancing innovation and technology transfer in the New Zealand apple industry - learnings from Apple Futures
}

\author{
N.M. Park ${ }^{1}$, T.A. Williams ${ }^{2}$, J.T.S. Walker ${ }^{1}$, M.R. Butcher ${ }^{3}$, J.A. Turner ${ }^{4}$, N. Botha ${ }^{4}$, \\ J. Vereijssen ${ }^{2}$ and N.M. Taylor ${ }^{1}$ \\ ${ }^{1}$ The New Zealand Institute for Plant E Food Research Limited, Private Bag 1401, \\ Havelock North 4130, New Zealand \\ ${ }^{2}$ The New Zealand Institute for Plant E Food Research Limited, Private Bag 4704, \\ Christchurch Mail Centre, Christchurch 8140, New Zealand \\ ${ }^{3}$ Pipfruit New Zealand Inc. (retired), Parua Bay, RD4, Whangarei, New Zealand \\ ${ }^{4}$ AgResearch, Ruakura Research Centre, Private Bag 3123, Hamilton 3240, New Zealand \\ Corresponding author: nicola.park@plantandfood.co.nz
}

\begin{abstract}
Apple Futures was a research implementation project designed to produce export quality, ultra-low residue apples while meeting the phytosanitary requirements of over 60 countries. In 3 years from 2007/08 to 2009/10 seasons it was successfully implemented on 65\% of New Zealand's export apple crop with a benefit-cost ratio of 30 times the value of the investment. The process of developing and implementing Apple Futures is the subject of a case study on co-innovation - an approach to solving complex problems that engages multiple stakeholders throughout research and extension initiatives to enhance adoption and impact. A new innovation system analysis framework was used to identify key co-innovation learnings. These included the importance of trust amongst participants, learning together, a clear agenda for change, and monitoring and evaluating progress towards that change agenda. Findings are discussed in the context of maximising impact in innovation projects in New Zealand's primary sector.
\end{abstract}

Keywords co-innovation, technology transfer, IPM, agricultural innovation system.

\section{INTRODUCTION}

\section{Apple Futures}

Apple Futures was a project designed to implement applied research across a national industry. Launched in 2007 Apple Futures was designed to meet new demands from key European Union (EU)/United Kingdom (UK) markets for ultralow residue apples and halt the decline of returns to the New Zealand apple growers (Pipfruit NZ Inc. 2014; Walker et al. 2015). EU regulatory changes were leading to deregistration of some pesticides and lowering maximum residue limits (MRL) (European Parliament and Council 2005) while consumer demands for safer food continued to drive supermarkets to implement yet more stringent food safety and environmentally and socially responsible production standards (Walker et al. 2001). At a time when $68 \%$ of New Zealand's 295,412 tonnes of export apples were sold in UK, Ireland and Continental Europe (Pipfruit NZ Inc. 2012), retaining this market and at a premium return, was critical to apple growers.

The goal of Apple Futures was to introduce national industry guidelines for producing 
apples with nil detectable residues while meeting the phytosanitary requirements of around 68 countries (Butcher 2007). The specific targets were: (1) develop guidelines for ultra-low residue fruit production; (2) evaluate the issues and risks in a pilot programme on commercial orchards; (3) develop an implementation strategy; (4) meet the needs of growers nationally giving consideration to each unique region; (5) deliver marketable quality fruit with nil detectable residue levels; and (6) recommend orchard management techniques and agrichemicals to ensure a residue profile of no more than three residues detected and with mean residues detected $\leq 10 \%$ of the EU MRLs if nil residues was unachievable.

Programme impact assessments describe a rapid development and uptake of Apple Futures. By the 2010 season, $61 \%$ of national planted area (8849 ha) was grown following Apple Futures (Pipfruit NZ Inc. 2012). Mean pesticide residues were consistently low 9\% EU MRL. Pesticide frequency was $\leq 3$ residues per fruit sample on $93 \%$ of apples tested and $72 \%$ were free from detectable insecticide residues (Walker et al. 2015). Economic assessments by the NZ Institute of Economic Research (NZIER) estimated the value generated by Apple Futures was 30 times the cost of the research (Kaye-Blake \& Zuccollo 2012), and this was achieved during the global financial crisis when consumer demand for premium products had declined.

\section{Primary Innovation Programme}

Apple Futures was one of four case studies retrospectively evaluated in a research programme that aims to stimulate innovation in New Zealand's primary sector (Botha et al. 2014). Working with scientists from Wageningen University (The Netherlands), the MBIE-funded Primary Innovation team, led by AgResearch, followed an agricultural innovation systems (AIS) approach to assessing nine co-innovation principles in the Apple Futures project. These principles include the need for effective networks, interaction, learning and a shared challenge or opportunity (Nederlof et al. 2011).

An AIS approach was chosen because it gives a comprehensive view of all the factors and stakeholders that together determine innovation outcomes. This paper describes key learnings from Apple Futures using the AIS analysis framework developed by Wieczorek \& Hekkert (2012). Findings are discussed in the context of maximising impact of innovation projects in New Zealand's primary sector.

\section{METHODS}

\section{Innovation framework analytical tool}

Designed as a policy tool to describe an innovation system and its problems, the Wieczorek \& Hekkert (2012) AIS framework integrates a structural analysis, i.e. actors, institutions (soft, e.g. values; hard, e.g. legislation), interactions (networks and individual contacts) and infrastructure (financial, knowledge, expertise and physical factors) with a functional analysis (Table 1). This framework provides diagnostic questions for each function to identify how they were operating and the extent of capability in each of the structures within that function.

\section{Analysis and sources of information}

Like most research diagnosing agricultural innovation systems (AIS) work (Lamprinopoulou et al. 2014), the present study was based on a literature review complemented by semi-structured interviews. Semi-structured interviews were carried out to give the interviewer the flexibility to explore topics of interest raised by interviewees creating more in-depth interviews (Patton 1990). Interview questions were based on diagnostic questions from Wieczorek \& Hekkert (2012). The aim of the interviews was to obtain an understanding of the factors that participants in Apple Futures perceived to be key in the programme's success. The theoretical framework was applied to code literature and interviews. The interviewers jointly conducted analysis of the coded literature and interviews to identify themes across interviewees and the literature. Follow-up conversations to share emerging themes with the interviewees were used to validate and deepen the initial findings.

The primary source of information was the existing literature on Apple Futures, including technical presentations, reports, industry newsletters, newspapers, etc.; 95 documents were catalogued. Interviews with two project 
Table 1 Functions of an innovation system (Hekkert et al. 2007; Wieczorek \& Hekkert 2012)

\begin{tabular}{|c|c|}
\hline Function & Description \\
\hline F1: Entrepreneurial activities & $\begin{array}{l}\text { Activities, individuals or groups that identify potential and act on it } \\
\text { while managing risk often through experimentation }\end{array}$ \\
\hline F2: Knowledge development & $\begin{array}{l}\text { Processes of learning such as 'learning by searching for information', } \\
\text { or 'learning by doing' }\end{array}$ \\
\hline F3: Knowledge exchange & $\begin{array}{l}\text { Knowledge diffusion through networks; learning by interacting, or } \\
\text { 'learning by using' }\end{array}$ \\
\hline F4: Guidance of the search & $\begin{array}{l}\text { Activities that positively affect the visibility and clarity of specific } \\
\text { needs and goals }\end{array}$ \\
\hline F5: Market formation & $\begin{array}{l}\text { Mechanisms to allow for further development and learning of the } \\
\text { initial version of the innovation (F2 \& F3) and develop expectations } \\
\text { (F4), e.g. through financial incentives or niche uses }\end{array}$ \\
\hline F6: Resources & Sufficient knowledge, financial and human resources \\
\hline F7: Creation of legitimacy & $\begin{array}{l}\text { Advocacy to catalyse change through activities such as identifying and } \\
\text { discussing the need (F4), finding resources (F6), creating incentives (F5) }\end{array}$ \\
\hline
\end{tabular}

members completed in July 2014 were recorded, transcribed and coded against the structures and functions framework. Commentary gained from these interviews complemented quotes extracted from the literature to create a rich source of perspectives on success factors. A timeline analysis (van Mierlo et al. 2010) highlighting key events, gave context to the study, structure to the interviews and identified the success and challenges experienced by stakeholders in Apple Futures.

\section{RESULTS AND DISCUSSION}

This narrative of Apple Futures follows the timeline of key events, commencing with the inception of IFP in 1995. The functions from the AIS analysis are shown in brackets. The themes that emerged from the analysis highlighted the importance of clear drivers and goals with measurable targets [F1, F4, F5, F7], strong leadership and project management with regional collaboration and significant resourcing [F6, F7] and an integration of knowledge and practices refined through experience [F2, F3]. The pilot programme gave confidence in the concept [F2, F6, F7], while communication, grower learning through discussion groups [F2, F3] in collaboration with a trusted project team $[\mathrm{F} 1, \mathrm{~F} 7]$ and getting growers on board [F2, F3, F5, F6, F7] were all key to managing challenges and to the project's ultimate success.

\section{Clear drivers, clear goals}

In 2005 economic returns to apple growers had plummeted for a variety of reasons, including supply, market and fiscal policy (Figure 1) (Ministry of Agriculture and Forestry 2005; Innomarc Consulting Ltd 2006). Industry reviews gave high priority to urgently establishing a nil discernible residue programme while exporter feedback gave clear targets indicating EU/UK supermarket standards of $30-50 \%$ of the regulatory EU MRL [F5]. To account for all export market customers a target of $\leq 10 \%$ of the EU MRL was set to achieve a "universally marketable apple". As a project team member explained, "a threat became an opportunity" [F1]. The project design included setting clear targets, as a project team member clarified "So if you've got a target to work to, you've got a series of measures to know how you're going". A clear need for change had been established at an industry and national level. This gave the subsequent Apple Future project clear goals, measurable targets [F4] and legitimacy [F7].

\section{Apple Futures combining a toolbox of approaches}

While driven by new EU regulatory and supermarket demands, the origins of Apple Futures go back to 1995 with the inception of the Integrated Fruit Production (IFP) programme. Pipfruit NZ Inc. and Plant \& Food Research 
scientists assessed the current industry IFP programme against the new targets. Prior to Apple Futures, mean residues were low, typically $<20 \%$ of EU MRLs (Walker et al. 2015). To achieve the lower $\leq 10 \%$ target consistently, a project team member described "This was something we could achieve. We always knew we could do better." Apple Futures integrated the current toolbox of crop protection knowledge and practices [F2] to maximise biological and cultural controls and enhance IPM monitoring responses, concentrating on early season management. The project team used the phrase "Do it better early - then relax late". Refining this approach through grower experience supported by discussion groups and extensive monitoring of progress was the focus of the Apple Futures project team [F3].

\section{PipSafe pilot programme}

Commencing in August 2006, MAF's Sustainable Farming Fund and Pipfruit NZ Inc. jointly funded PipSafe, a pilot programme to develop an ultra-low residue production system [F6]. Growers evaluated the new programme [F2] on
1-2 ha blocks of an early- and late- maturing apple cultivar, supported by their supply group and extensively monitored by researchers. These "were growers that had been at the forefront of the introduction of IFP in the mid-90s and could see that there were likely to be benefits and had the experience to trust what we were doing" (project team). PipSafe was first introduced to Hawke's Bay close to the science team with five growers, then to Nelson the next season with a further eight growers to address regional differences due to climate. PipSafe was successful in producing ultra-low residue fruit of market quality and became the pilot for the national adoption of Apple Futures (Butcher 2007). A member of the project team explained the pilot success gave confidence, "We could relay what we thought were going to be robust programmes for continued European access to the industry" [F7].

\section{Resourcing and regional collaboration}

In July 2007 the Government announced a \$2M, 3-year, multi-regional collaborative project to produce export apples with no detectable residues (Mallard 2007). The project was a partnership

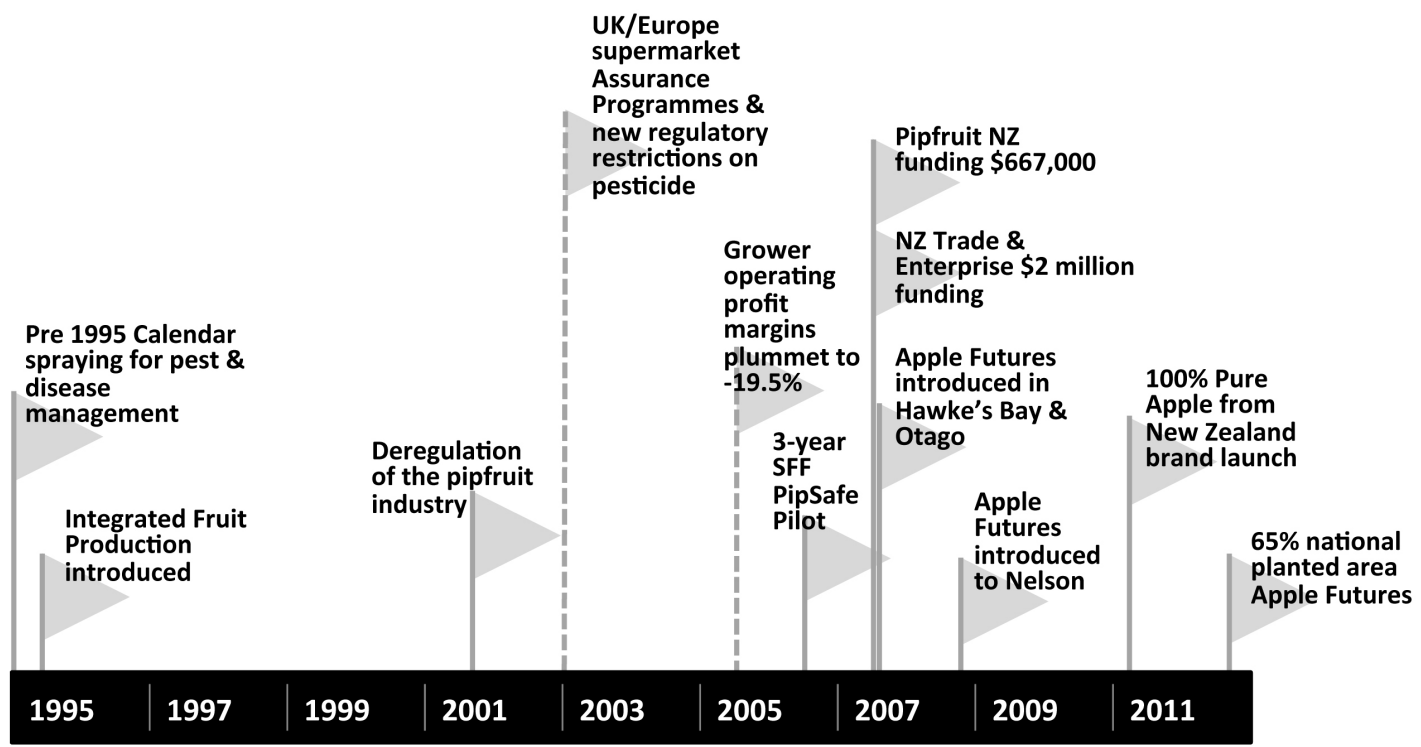

Figure 1 Timeline of Apple Futures key events from 1995 to 2012. 
between New Zealand Trade and Enterprise, the regional economic development agencies (EDAs) in Hawke's Bay, Nelson and Otago and Pipfruit NZ Inc. which contributed an additional $\$ 667,000$. Backed by an industry strategy [F4] to become a leading international niche player [F5], stopping the current decline in returns and enhancing pipfruit export performance was seen as critical to the regions [F7]. A unique collaboration between industry, regional EDAs and research focused on the implementation of Apple Futures. Project team members described the funding as critical. "We wouldn't have been able to introduce Apple Futures over a 3-year period to the whole industry and get the buy-in that we had, had we not had the funding in one big pool to do that" [F6, F7].

\section{Leadership and project management}

The Apple Futures Board included regional representation from Hawke's Bay Inc, Nelson Regional EDA, Otago Forward and three regional Pipfruit NZ Inc. representatives. The board chair was Julian Raine, a Nelson grower and industry leader [F7]. With strong leadership from Pipfruit NZ Inc., the Apple Futures project team consisted of a Project Manager, three regional coordinators, technical advisor from Pipfruit NZ Inc., and a small team of science advisors from Plant \& Food Research (Austin-Smith 2008). A member of the project team noted in interviews that "Having those co-ordinator and business manager roles in place took a lot of the day-to-day running of the roll out away ... so that we could concentrate on the actual programme itself and where we thought we needed to place emphasis" [F6]. The three regional co-ordinators identified issues, were a local point of contact, collected fruit samples and facilitated discussion groups. They had "technical expertise in the industry and they could guide the discussions; they could interpret the science" (project team). The scientists from Plant \& Food Research were largely the same science team that had developed the original IFP programme. The project team described this trust in the scientists as critical to the success of Apple Futures. "In part due to success of previous IFP. They trusted the team" [F6, F7].

\section{Getting growers on board}

Interest in Apple Futures was high with 390 orchards $(38 \%)$ registering in the first year. The success of PipSafe was key to introducing the programme to the wider industry. A project team member explained "We had to get buy-in, therefore we had to have as much assurance around the programmes that we were going to put forward to them as possible, and that's what Pipsafe was about". Rolling that out to the industry, a process similar to IFP was used [F6]. The previously successful process gave growers confidence in the project as noted by a project team member who commented "IFP programme process gave confidence. Nobody lost their shirt previously". Trust was also a key component expressed by a project team member. "I don't believe you can get an industry working to the level that it is willing to make changes to its production programmes almost on an annual basis, to refine them, without having confidence in the people who are making those recommendations."

Registering for Apple Futures, growers undertook to share spray diaries and residue results and as an incentive the residue tests were significantly discounted [F5, F6]. The residue data were critical for programme development [F2] and gave individual growers direct feedback on their progress with adopting the Apple Futures technology [F3]. The project team observed a growing demand from exporters for Apple Futures for fruit going to the EU " $a$ downward push from exporters to growers" with exporters saying "if you want us to take your fruit you've got to do Apple Futures" [F5, F7].

\section{Learning by doing, learning by interacting}

While there was already excellent capability within the industry, Apple Futures was an even more strategic approach to crop protection [F6]. The project team message to growers was "The leap for you, going into Apple Futures is not as big as the leap you took when you went into IFP". The discussion groups were critical for growers and the science team. The project team noted "Getting on their properties, joint discussions, provide information back to growers, on same page. This leads to trust, information and knowledge sharing" [F2, F3]. 
Discussions were a social occasion to support learning "sharing successes and mistakes" The regional co-ordinators actively facilitated this process, creating groups of 8 to 10 growers and also using existing packhouse supply group structures [F3].

Scientists supported the regional co-ordinators where issues could not be answered within the group. Apple Futures regional newsletters, web-based tools, weekly Pipfruit NZ Inc. emails, wallcharts and industry technical seminars provided support. Small regional grower workshops at key decision times were an opportunity to debate directly with the science team. A project team member recalled "The scientists were at the meetings. They were hearing the problems or what was a success" [F2, F3]. Separate workshops were held with pipfruit consultants, agrichemical companies and merchants to ensure consistent advice was given. A project team member explained "If you get conflicting advice out there you start getting confusion and people not accepting that there's a robust programme behind it. You have to have a consistent message" [F7].

\section{Managing challenges}

From the outset consideration was given to the potential impacts of the project. Pipfruit NZ Inc. funded a business case analysis [F1] with the outcome giving economic justification for the project with the alternative a continuing downward decline in exports (Kaye-Blake \& Zuccollo 2012). Following this, the pilot programme needed to be a success, explained a project team member. "We had to have successes in the initial groups. If we hadn't had success in those groups the jungle telegraph would have killed the project for future years" [F7]. Communication and a timely response were important for addressing grower and board concerns and enabled changes to the PipSafe and Apple Futures programmes. A project team member described "It was making sure messages were got out there as clearly and as quickly as possible". Scientists debated the programmes directly with growers in discussion groups and regional co-ordinators had a key role in highlighting concerns and learnings back to the science team [F2, F3].

Seasonal and regional differences to pest and disease pressures in Apple Futures blocks were closely monitored by growers, crop monitors and consultants (Park \& Walker 2011). Crop monitor pest and disease incidence data, spray diary and residue test data were made available to the science team [F2, F3]. Data management tools for analysing the 3000 residue tests and 7000 apple block spray diaries were developed and continue to be used by Pipfruit NZ Inc. for the National Pipfruit Random Residue Testing programme that underpins Apple Futures [F7].

Issues affecting pest and disease outcomes needed to be swiftly dealt with even if it was not caused by Apple Futures [F1]. In 2008, an outbreak of woolly apple aphid (Eriosoma lanigerum) (WAA) due to the disruption of biological control by the endoparasitoid Aphelinus mali was initially blamed on Apple Futures (Rogers et al. 2011). Additional funding was provided by Pipfruit NZ Inc. [F6] to determine the basis of this disruption to biological control by A. mali. Based on the investigation [F2], the Apple Futures team provided management advice for growers affected by the insecticide-induced outbreak and best practices for the industry going forward before the next season [F3] (Rogers et al. 2015).

In 2009 a warm August in Nelson ( 1 in 64 year event) resulted in early bud burst and potentially early black spot ascospore (Venturia inaequalis) release prior to early season fungicide applications. Black spot disease levels on some blocks were high "worst seen in 30 years of orcharding" (Nelson grower) (P.N. Wood, Plant \& Food Research, personal communication). Again while not caused by Apple Futures, the Apple Futures team was proactive in working with growers [F2, F3] to identify the cause and best practices for managing high levels of black spot incidence (Beresford et al. 2012).

Meeting the phytosanitary and residue requirements of 65 countries had challenges. The project and science team members interviewed noted further programme development was needed particularly for the growing Asian market [F1, F5]. In 2014 the New Zealand Government announced that Pipfruit NZ Inc. would receive $\$ 4.35 \mathrm{M}$ over 7 years for Apple Futures II, a partnership programme that aims to improve phytosanitary outcomes for enhanced access into high value Asian markets (Joyce \& Guy 2014). 


\section{Marketing and intellectual property}

While Apple Futures was a further development of IFP, it was given its own identity. A project member explained "Well it had to because if we'd just left it as IFP, then there is no step gain. People don't see a difference". To address industry concern that IFP had not been adequately protected or marketed, at the commencement of Apple Futures the board contracted a patent attorney to review the IP of Apple Futures [F1] (AustinSmith 2008). With many individual business brands, branding is difficult. The Pipfruit NZ Inc. Market Panel of exporters considered options working with supermarket buyers rather than directly with consumers where a lowresidue message is difficult to communicate. The option of a small endorsement brand to support business brands was explored. In 2011 Pipfruit NZ Inc. launched the brand " $100 \%$ Pure Apples from New Zealand" at the Cricket World Cup (Fox 2011) [F5]. Apple Futures underpins the 100\% Pure Apples from New Zealand brand (www.produceofnewzealand.org/).

\section{CONCLUSION}

The success of Apple Futures can be attributed to the following key innovation project features. There were clear drivers and clear goals with measureable targets. Strong leadership from Pipfruit NZ Inc. and the Apple Futures Board kept the project on target and created an environment for the project to operate through advocacy, resourcing and incentives. Project management, marketing and IP were addressed from the start by a dedicated business manager and experienced board. Cyclic communication was timely and regular with growers, exporters and all involved in pipfruit crop protection. The pilot programme was essential to demonstrating the concept and managing the risks. Extensive monitoring of the key components of PipSafe and Apple Futures tracked progress. The trusted science team with a track record of success was pivotal in securing adoption. Learning supported by Pipfruit NZ Inc. facilitated discussion groups that enabled growers to have direct dialogue with scientists was invaluable. Growers gained greater knowledge of systems, pests, predators and diseases that can be applied to meet new challenges. Apple Futures continues to adapt and develop to meet changing market needs.

\section{ACKNOWLEDGEMENTS}

Pipfruit NZ Inc. for providing partial funding and access to historical documents, interviews and paper review. New Zealand Trade and Industry and Pipfruit NZ Inc. for funding Apple Futures and to growers, Apple Futures Board and the Apple Futures team for a job well done that has been a privilege to share. The Ministry for Business, Innovation and Employment (MBIE) for funding Co-learning and co-innovation to achieve impact - a new era in technology transfer for New Zealand's biological industries - Primary Innovation (C10X1204).

\section{REFERENCES}

Austin-Smith J 2008. Background and Project Management. 2008 Nelson Technical Seminar. Pipfruit NZ Inc, Hastings, New Zealand.

Beresford RM, Wright PJ, Wood PN, Park NM 2012. Sensitivity of Venturia inaequalis to myclobutanil, penconazole and dodine in relation to fungicide use in Hawke's Bay apple orchards. New Zealand Plant Protection 65: 106-113.

Botha N, Klerkx L, Small B, Turner J 2014. Using co-innovation to stimulate innovation in the New Zealand Agricultural sector. 11th European IFSA Symposium. Berlin, Germany. Pp. 232-239.

Butcher M 2007. A word from the Technical Manager. Pipfruit NEWZ. Pipfruit NZ Inc., Hastings, New Zealand.

European Parliament and Council 2005. Regulation (EC) No 396/2005 on maximum residue levels of pesticides in or on food and feed of plant and animal origin. http://eur-lex.europa.eu/ legal-content/EN/TXT/PDF/?uri=CELEX:320 05R0396\&rid=1. (accessed 13/04/2015).

Fox A 2011. 100\% Pure NZ Apples Brand Pitched at India. NZFarmer.co.nz. Fairfax New Zealand Ltd. 21 March 2011. http://www.stuff.co.nz/ business/farming/4789768/100-pure-NZapples-brand-pitched-at-India (accessed 21/02/2014). 
Hekkert M, Suurs R, Negro S, Kuhlmann S, Smits R 2007. Functions of innovation systems: A new approach for analysing technological change. Technological Forecasting \& Social Change 74: 413-432.

Innomarc Consulting Ltd 2006. Smarter, Faster, Better - Leading Niche Player. A development strategy for the NZ Pipfruit Industry. Innomarc Consulting Ltd. Wellington. http://www. coriolisresearch.com/pdfs/PNZ_STRATEGIC_ REPORT.pdf (accessed 5/08/2013). 78 pp.

Joyce S, Guy N 2014. $\$ 15 \mathrm{~m}$ for new biological research partnerships. Press release 28 October 2014. beehive.co.nz, New Zealand Government. http://beehive.govt.nz/ release/15m-new-biological-researchpartnerships (accessed 20/01/2015).

Kaye-Blake W, Zuccollo J 2012. The economic impacts of the Apple Futures programme. Conference of the New Zealand Association of Economists. 27 June 2012. Palmerston North, New Zealand. 36 pp.

Lamprinopoulou C, Renwick A, Klerkx L, Hermans F, Roep D 2014. Application of an integrated systemic framework for analysing agricultural innovation systems and informing innovation policies: Comparing the Dutch and Scottish agrifood sectors. Agricultural Systems 129: 40-54.

Mallard T 2007. Groundbreaking Apple Futures programme launched. Press release. 25 July 2007. New Zealand Government. http://www.beehive. govt.nz/release/groundbreaking-apple-futuresproject-launched (accessed 22/02/2014).

Ministry of Agriculture and Forestry 2005. Pipfruit Monitoring Report. Ministry for Primary Industries, Wellington, New Zealand. http://www.mpi.govt.nz/news-resources/ publications?title $=$ farm $\% 20$ monitoring $\% 20$ report (accessed 24/02/2014). 28 pp.

Nederlof S, Wongtschowski M, van der Lee F ed. 2011. Putting heads together. Agricultural innovations platforms in practice, Bulletin 396. Royal Tropical Institute (KIT), Amsterdam, The Netherlands. 192 pp.

Park NM, Walker JTS 2011. Apple Futures 20082010. Final Report. Client report 6036. Plant \&
Food Research, Auckland. New Zealand. 60 pp.

Patton MQ 1990. Qualitative evaluation and research methods. Second edition. SAGE Publications Inc., USA. 532 pp.

Pipfruit New Zealand Inc. 2012. Pipfruit industry statistical annual 2011. Pipfruit New Zealand Inc, Hastings, New Zealand. 33 pp.

Pipfruit New Zealand Inc. 2014. 100\% Pure apples from New Zealand http://www. produceofnewzealand.org/ (accessed 29/08/2014).

Rogers DJ, Sharma N, Stretton DC, Walker JTS 2011. Toxicity of pesticides to Aphelinus mali, the parasatoid of woolly apple aphid. New Zealand Plant Protection 64: 235-240.

Rogers DJ, Lo PL, Walker JTS 2015. Vulnerability of pest management in New Zealand apples: pesticide toxicity to Aphelinus mali (Hymenoptera: Encyrtidae). New Zealand Plant Protection 68: 299-305.

van Mierlo B, Regeer B, van Amstel M, Arkesteijn M, Beekman V, Bunders J, de Cock Buning T, Elzen B, Hoes A, Leeuwis C 2010. Reflexive monitoring in action. A guide for monitoring system innovation projects. Wageningen/Amsterdam, Communication and Innovations Studies, WUR; Athena Institute, VU www.wageningenur.nl/en/ show/Reflexive-Monitoring-in-Action.htm (accessed 25/02/2014). 106 pp.

Walker JTS, Park NM, Butcher MR 2015. Apple Futures: New Zealand's low pesticide residue apple production programme. New Zealand Plant Protection 68: 282-290.

Walker JTS, Manktelow DWL, Wearing CH, Lo PL, Suckling DM 2001. Development of integrated fruit production programmes in the New Zealand horticultural industry. Bulletin OILB/SROP, v. 24. International Organization for Biological and Integrated Control of Noxious Animals and Plants, Dijon, France. Pp. 39-44.

Wieczorek AJ, Hekkert MP 2012. Systemic instrument for systemic innovation problems: A framework for policy makers and innovation scholars. Science and Policy 39: 74-87. 